\title{
PRÁTICAS EM BIOGEOGRAFIA COMO ALTERNATIVA PARA AÇÕES DE EDUCAÇÃO AMBIENTAL
}

\author{
Rodrigo Corrêa Pontes ${ }^{(a)}$ Naijara Klafke Dalla Lana ${ }^{(b)}$ Cibele Stefano ${ }^{(c)}$ Mauro Kumpfer \\ Werlang ${ }^{(d)}$
}

(a) Departamento de Geociências/ Universidade Federal de Santa Maria, Email: rodrigocorreapontes@gmail.com

(b) Departamento de Geociências /Universidade Federal de Santa Maria, Email: naijaraklafke@ hotmail.com

(c) Departamento de Geociências /Universidade Federal de Santa Maria, Email: cibele2012stefanno@ gmail.com

(d) Departamento de Geociências /Universidade Federal de Santa Maria, Email: wermakwer@gmail.com

\section{EIXO 7: GEOGRAFIA FÍSICA - CURRÍCULO, FORMAÇÃO E PRÁTICAS DE ENSINO}

\begin{abstract}
Resumo
O trabalho relata o desenvolvimento de um projeto de extensão visando promover práticas em Educação Ambiental. Para a aplicação da atividade foi designada uma turma do Colégio Técnico Industrial da Universidade Federal de Santa Maria, no Município de Santa Maria, no Estado do Rio Grande do Sul, Brasil. A atividade foi realizada através de uma aula expositiva com cerca de cinquenta espécies ameaçadas de extinção no estado do Rio Grande do Sul, apresentando seus habitats naturais e peculiaridades. A proposta buscou estimular os estudantes à visualização, identificação, reflexão, discussão e sensibilização perante a temática da natureza, onde se procurou promover uma atitude reflexiva e crítica sobre ameaças aos ecossistemas. A partir dessa reflexão, delineou-se uma relação de interdependência entre os seres vivos e a natureza. Após essa atividade foi elaborada uma trilha, onde os estudantes tiveram oportunidade de visualizar algumas espécies endêmicas e remanescentes da cobertura vegetal original da região.
\end{abstract}

Palavras chave: Biogeografia, Educação Ambiental, Rio Grande do Sul.

\section{Introdução}

Nas últimas décadas a ação antrópica tem perturbado irreversivelmente o meio ambiente através da utilização dos ecossistemas naturais. Em razão da modernização do homem no campo, a expansão agrícola, juntamente com a criação de gado extensiva e a silvicultura têm impactado diretamente esses ambientes, sendo alguns considerados frágeis por estarem representados em áreas de pequena extensão e por abrigarem espécies vegetais endêmicas e ameaçadas de extinção. Esse avanço desenfreado tem comprometido e colocado em risco de extinção diversas populações de espécies da flora nativa, mais especialmente ameaçadas pelo avanço da produção de monoculturas agrícolas (como por exemplo, a soja) e pelo reflorestamento desordenado com espécies exóticas.

A demanda comercial do sistema vigente e a cobiça de uma rápida obtenção de lucros contribuem para o aumento da produção, que conseqüentemente, irão comprometer e impactar novas áreas para desenvolver seus plantios. Estes fatores, associados com a ausência de consciência ambiental acarretam a degeneração 
do meio ambiente e toda sua cadeia envolvida. Sendo assim, o atual comportamento ambiental do homem é uma grande ameaça a existência de diversas formas de vida, inclusive a da própria raça humana.

Dentro deste panorama, as áreas campestres são muito visadas, devido à ausência de densidade florestal e a topografia relativamente plana para os cultivos agrícolas. Ao observar o crescente problema, buscam-se alternativas que auxiliem a identificar, gerenciar e preservar estas áreas com grande relevância ambiental no aspecto florístico, sem comprometer as condições naturais e seus processos ecológicos.

$\mathrm{Na}$ atualidade as discussões sobre o meio ambiente e sua biodiversidade vêm tidas como desafio para os órgãos públicos, privados e a sociedade em geral, aonde se debatem a preservação e conservação dos ecossistemas, esses cada vez mais ameaçados pela pressão do modelo econômico mundial. Percebemos que o mundo aos poucos está sendo consumido pelo capital, ou seja, florestas e campos com significativa biodiversidade florística e faunística estão sendo ocupados por monoculturas extensivas, colocando em risco a sobrevivência de espécies endêmicas e com grande importância dentro do ciclo ecológico.

Segundo Troppmair (2012) a paisagem modificada pelo homem coloca em risco a sobrevivência de espécies da fauna e flora que a constituem. Por esse motivo práticas ambientais devem ser elaboradas para a conscientização das pessoas á respeito da importância da natureza. As práticas ambientais procuram sensibilizar o homem para a questão do papel da natureza no meio ambiente assim como inserir o homem dentro da mesma, demonstrando sua importância como protetor.

É necessário ter ciência da natureza, tanto para sua compreensão quanto para sua importância e relações com os diversos seres vivos, incluindo o homem. Sem o conhecimento e a compreensão da importância do meio ambiente não há como cobrar da sociedade uma atitude justa perante a causa. Em razão da situação presente, tornam-se necessárias práticas de educação ambiental, buscando aproximar o homem à natureza, principalmente às plantas e respectivamente aos seus habitats naturais.

Esse projeto visa à educação ambiental, a partir de práticas ambientais, buscando uma aproximação dos estudantes com a natureza, gerando e estimulando vínculos emocionais a fim de permitir a ampliação das percepções, demonstrando as inúmeras peculiaridades do reino das plantas e a íntima relação delas com os ambientes naturais.

\section{Objetivos}

A ação tem como objetivo geral proporcionar aos estudantes um panorama atual sobre diversas as espécies endêmicas nativas do Estado do Rio Grande do Sul, visando a conscientizarão da preservação e conservação de seus respectivos ambientes. Também procura desenvolver um dia de práticas de Educação Ambiental para o reconhecimento e registro das espécies sob a perspectiva de uma prática ambiental. 
Espera-se que a ação contribua no sentido de oportunizar um instrumento pedagógico prático e dinâmico, proporcionando uma aproximação da realidade do tema abordado com o cotidiano dos participantes, permitindo-lhes uma dinâmica de observação, reflexão e de sensibilização perante a natureza visualizada. As ações de extensão, em específico as práticas ambientais, devem proporcionar atividades que revelem o significado e as características do ambiente por meio de elementos naturais, por experiência direta, sendo assim um instrumento básico de educação ao ar livre. Soma-se a isso a natureza, no caso o ambiente englobado pela coleção botânica, como possibilidade de construção de conhecimento. A atividade corresponde a um instrumento pedagógico prático e dinâmico, proporcionando aproximação da realidade do tema abordado. Proporciona diversidade de atividades com custo relativamente baixo.

Como objetivo específico, a atividade oportunizar aos estudantes do Colégio Técnico Industrial da Universidade Federal de Santa Maria uma reflexão das relações dos seres vivos na natureza, utilizando-se recursos teóricos, fotográficos e exemplares da composição florística e da estrutura da Coleção Botânica do Colégio Politécnico da Universidade Federal de Santa Maria como local para discussão, observação, identificação, reflexão, registro de espécies e sensibilização dos alunos perante a natureza.

\section{Fundamentação teórica}

Nas últimas décadas, temos presenciado um grande e significativo crescimento dos movimentos ambientalistas e do interesse pela temática da preservação ambiental. Cada vez mais, tanto em países desenvolvidos e em vias de desenvolvimento, o homem está cada vez mais consciente de que o modelo atual de desenvolvimento econômico está associado à degradação e a destruição do meio ambiente e isso conseqüente e diretamente gera impactos na qualidade de vida e coloca em risco a sobrevivência da espécie humana.

Atualmente a mídia aborda temas como sustentabilidade e desenvolvimento sustentável, visando uma atitude da população perante o meio ambiente, mas, ao mesmo tempo cria modismos e as estimula a comprarem compulsivamente produtos para desta forma garantir a auto-alimentação do sistema econômico mundial capitalista, um modelo de desenvolvimento atual, desigual, excludente e esgotante dos recursos naturais. Para contrapor a essas atividades, discussões, reflexões e o interesse pelas questões ambientais são pertinentes, pois buscam aperfeiçoar e instigar o espírito crítico das pessoas fazendo-as repensarem suas atitudes perante o meio ambiente.

Em incontáveis locais podemos averiguar a degradação ambiental, tanto no ambiente urbano quanto no rural. No primeiro, podemos perceber resíduos provenientes da queima do petróleo (fuligem), poluição sonora e visual, esgoto cloacal sendo despejados nos cursos d'água, assim como resíduos industriais. 
É perceptível também a forma de como são tratados os resíduos sólidos, que geralmente é acumulado em lixões. No ambiente rural, o uso de agrotóxicos coloca em risco não só a vida do homem, mas também de animais como insetos (essenciais para a polinização de espécies nativas), mamíferos, aves e peixes, atingindo toda cadeia alimentar. Fertilizantes nitrogenados e dejetos oriundos da produção animal são despejados livremente nos cursos d'agua, colaborando para processos de eutrofização da água. A supressão da cobertura vegetal, erosão do solo, queimadas (coivaras) e assoreamentos dos cursos d'agua também são grandes problemas presentes. Em ambos ambientes (rural e urbano), espécies de flora e fauna são afetadas, levando-as a um processo de extinção.

Em razão disso, deve-se estimular a participação e interesse da sociedade para a temática da preservação, um tema fundamental no processo de reversão e compensação dos diversos problemas ambientais da atualidade. Ações educativas buscando a sensibilização, valorização e preservação do meio ambiente não deve ser uma tarefa exclusiva dos órgãos governamentais, pois a realidade demonstra que o Estado, apesar de dotado de leis, normas, regulamentos e fiscalização punitiva, o mesmo não consegue controlar o rápido avanço da degradação ambiental.

As formalidades burocráticas são muito lentas comparadas ao avanço da degradação dos ecossistemas. Uma das diversas possíveis respostas para todas essas questões abordadas acima, é o consórcio entre o desenvolvimento e a conservação/preservação, mas essa ferramenta só é ativa quando há o envolvimento da sociedade em um todo, no coletivo. Mas para o êxito, a sociedade deve comprometer-se e estar disposta a colaborar a trabalhar junto com os órgãos governamentais.

Um dos conceitos-chave para a Educação Ambiental é o de desenvolvimento sustentável. Esse conceito foi utilizado pela primeira vez no documento Estratégia de Conservação Global (World Conservation Strategy), que foi publicado pela World Conservation Union no ano de 1980. Mas foi a partir da publicação do Relatório: "Nosso Futuro Comum" em 1987 que o termo passou a ser mundialmente conhecido. A definição traz que o desenvolvimento sustentável é aquele que atende às necessidades do presente sem comprometer a possibilidade de gerações futuras atenderem às suas próprias necessidades.

No documento da Conferência das Nações Unidas sobre Meio Ambiente e Desenvolvimento - Rio 92, a Agenda 21, define desenvolvimento sustentável como "um desenvolvimento com vistas a uma ordem econômica internacional mais justa, incorporando as mais recentes preocupações ambientais, sociais, culturais e econômicas".

Um dos eventos mundiais mais importantes para a Educação Ambiental pós ECO-92, foi a "Conferência Meio Ambiente e Sociedade: Educação e Consciência Pública para a Sustentabilidade”, promovida pela UNESCO, em dezembro de 1997, na cidade de Thessaloniki, Grécia. Conhecido como a Declaração de Thessaloniki, o evento destaca que os governos e líderes mundiais honrem seus compromissos já 
assumidos durante as conferências da ONU e dêem à educação os meio necessários para que cumpra seu papel pela busca de uma futura sustentabilidade, que as escolas sejam encorajadas e apoiadas para que ajustem seus currículos em direção a um futuro sustentável, que todas as áreas temáticas, inclusive as ciências humanas e sociais, devem incluir as questões relacionadas ao meio ambiente e desenvolvimento sustentável, entre outras.

Segundo Marcatto (2002) a Educação Ambiental deve estar presente em todos os segmentos de ensino como tema transversal, sem a constituição de uma disciplina especifica como uma prática educativa integrada, envolvendo professores de todas as disciplinas, estes que deverão ser treinados para incluírem o tema nos diversos assuntos abordados em sala de aula.

Conforme a Política Nacional de Educação Ambiental, os princípios básicos da Educação Ambiental são: a) enfoque holístico, democrático e participativo; b) a concepção do meio ambiente em sua totalidade, considerando a interdependência entre o meio natural, sócio-econômico e o cultural, sob o enfoque da sustentabilidade; c) o pluralismo de idéias e concepções pedagógicas; d) a permanente avaliação crítica do processo educativo; e) a abordagem articulada das questões ambientais locais, regionais, nacionais e globais; f) a vinculação entre a ética, educação, trabalho e as práticas sociais e g) o reconhecimento e o respeito à pluralidade e à diversidade individual e cultural.

Marcatto (2002) ainda cita que a Política Nacional de Educação Ambiental possui como objetivos a democratização das informações, fortalecimento da consciência crítica sobre a problemática social e ambiental, incentivo à participação individual e coletiva na preservação do meio ambiente, o desenvolvimento de uma compreensão integrada do meio ambiente em suas múltiplas e complexas relações, entre outros.

\section{Metodologia}

Para a prática da Educação Ambiental, várias ferramentas e metodologias podem ser empregadas, objetivando através delas, a integração sócio-ambiental, o conhecimento científico da natureza e a mudança de comportamento do homem em relação ao seu entorno. Uma das práticas mais utilizadas na Educação Ambiental formal ou informal é a trilha temática, trilha essa que tem como objetivo ampliar a percepção ambiental e desenvolver uma visão crítica das questões ambientais para transformar os indivíduos em multiplicadores ambientais. Nesse contexto, percebe-se a existência de três trilhas distintas: a) Trilha interpretativa (temática): o planejamento da trilha é realizado em função de um tema definido, ao longo do percurso este tema pode ser desenvolvido em diferentes graus de complexidade em função da população-alvo; b) Trilha interpretativa (descoberta): o planejamento da trilha é realizado sem a definição 
prévia de um tema, ao longo do percurso o próprio grupo estabelece este objetivo; e c) Trilha interpretativa (turismo ecológico): o planejamento da trilha é realizado com ou sem a definição previa de um tema, ao longo do percurso são enfatizados aspectos sócio-econômicos e históricos da região. Tem como finalidade principal: o turismo e o lazer. Ao considerar essa abordagem, a atividade proposta pode ser enquadrada como uma trilha interpretativa temática na qual se desenvolvem temas pré-estabelecidos no decorrer do percurso definido.

Para a realização da atividade selecionou-se, preliminarmente, uma turma do primeiro grau do Ensino Médio do Colégio Técnico Industrial da Universidade de Santa Maria, os alunos do primeiro ano do ensino médio. O Colégio Técnico Industrial da Universidade de Santa Maria (CTISM) situa-se no Campus da Universidade Federal de Santa Maria (UFSM), no Bairro Camobi, na cidade de Santa Maria, RS. Pensando numa possibilidade de melhor aproveitamento para os participantes da ação, propôs-se a atividade para educandos do Ensino Médio, abrangendo uma faixa etária entre os 10 a 15 anos.

Troppmair (2012) destaca que nos níveis do ensino fundamental e médio, os alunos devem aprender as razões e os processos que se desenvolvem na natureza, para entender a função da mesma. Nesse sentido foi elaborada uma aula teórica, organizada através de uma apresentação didática e conceitual contendo informações acerca da Geografia e da Biogeografia. Utilizaram-se conceitos e definições teóricas, além de imagens e fotografias, buscando uma melhor compreensão por parte dos alunos. Foram selecionadas em torno de 50 espécies ameaçadas da flora nativa do Rio Grande do Sul (segundo Lista Final das Espécies da Flora Ameaçadas, contida no Decreto Estadual $n^{\circ} 42.099$, de 31 de dezembro de 2002) que serve de motivação inicial da atividade.

Destaca-se que essa etapa da ação poderá ser complementada em outras aulas, junto às disciplinas de Geografia e Biologia, nas turmas da escola, buscando integrar conhecimentos afins entre as disciplinas, utilizando-se as informações adquiridas pelos educandos, em suas vivências. A apresentação foi desenvolvida através da utilização da ferramenta do Power Point. Em seguida, foi realizada uma aula prática, onde os alunos percorreram o Campus da Universidade Federal de Santa Maria (UFSM) e a Coleção Botânica do Colégio Politécnico da UFSM e, assim, tiveram a oportunidade de visualizar algumas das particularidades no hábito e na morfologia das plantas. Para o desenvolvimento dessa etapa da ação, foram estabelecidos pontos de observação, aproveitando-se dos elementos naturais vegetais que existem no Campus da UFSM e na Coleção Botânica do Colégio Politécnico da UFSM.

A duração da atividade delimitou-se de acordo com a dimensão do trabalho a ser realizado e os conhecimentos abrangidos. Desta forma, definiu-se oito horas para a realização da atividade, divididas em dois encontros, sendo que pode ser aplicado em qualquer horário de um dia qualquer, excluindo o período noturno. Preferencialmente, selecionou-se o horário das $08 \mathrm{~h}: 00 \mathrm{~min}$. às $12 \mathrm{~h}: 00 \mathrm{~min}$. A atividade será 
organizada através de aulas teóricas expositivas, desenvolvendo conceitos básicos pertinentes à temática do meio ambiente.

Posteriormente selecionou-se em torno de 50 espécies ameaçadas da flora nativa do Rio Grande do Sul (segundo Lista Final das Espécies da Flora Ameaçadas, contida no Decreto Estadual nº 42.099, de 31 de dezembro de 2002) que serve de motivação inicial da atividade. Em seguida, realizou-se uma aula prática, onde os alunos percorreram o Campus da Universidade Federal de Santa Maria (UFSM) e a Coleção Botânica do Colégio Politécnico da UFSM para desta forma visualizar algumas espécies nativas e suas particularidades em hábito e morfologia.

Para caracterizar o objeto desta ação de extensão, percebe-se a necessidade de localizar-se no espaço. A implantação da Coleção Botânica do Colégio Politécnico da Universidade Federal de Santa Maria iniciou durante o ano 2000 com a cessão das áreas de silvicultura, fruticultura e culturas anuais para o setor de Jardinagem. Atualmente a coleção abriga uma grande variabilidade de espécies vegetais de diversas famílias botânicas servindo como base para estudos e outros fins didáticos. A área possui aproximadamente um hectare. O local de seu suporte físico situa-se no município de Santa Maria, RS. De acordo com Roos (1996) o relevo encontra-se área de transição geomorfológica entre os Planaltos e Chapadas da Bacia Sedimentar do Paraná e a Depressão Periférica Sul-Riograndense. No contexto, da região central do estado do Rio Grande do Sul e da Depressão Periférica Sul-Riograndense, é que está situada a área de estudo junto a Coleção Botânica do Colégio Politécnico da UFSM.

\section{Resultados e discussões}

A ação desenvolvida envolveu como previsto os alunos do Colégio Técnico Industrial da Universidade Federal de Santa Maria perante as tarefas propostas. A receptividade em frente à temática foi muito boa durante as aulas expositivas (figura 1), pois a maioria dos alunos acredita que o assunto é de grande valia para a sua formação como aluno e cidadão. Outro ponto positivo foi aprovação da proposta da prática, ou seja, sair do ambiente da sala de aula, em busca de diferentes de espécies presentes em nosso cotidiano. 

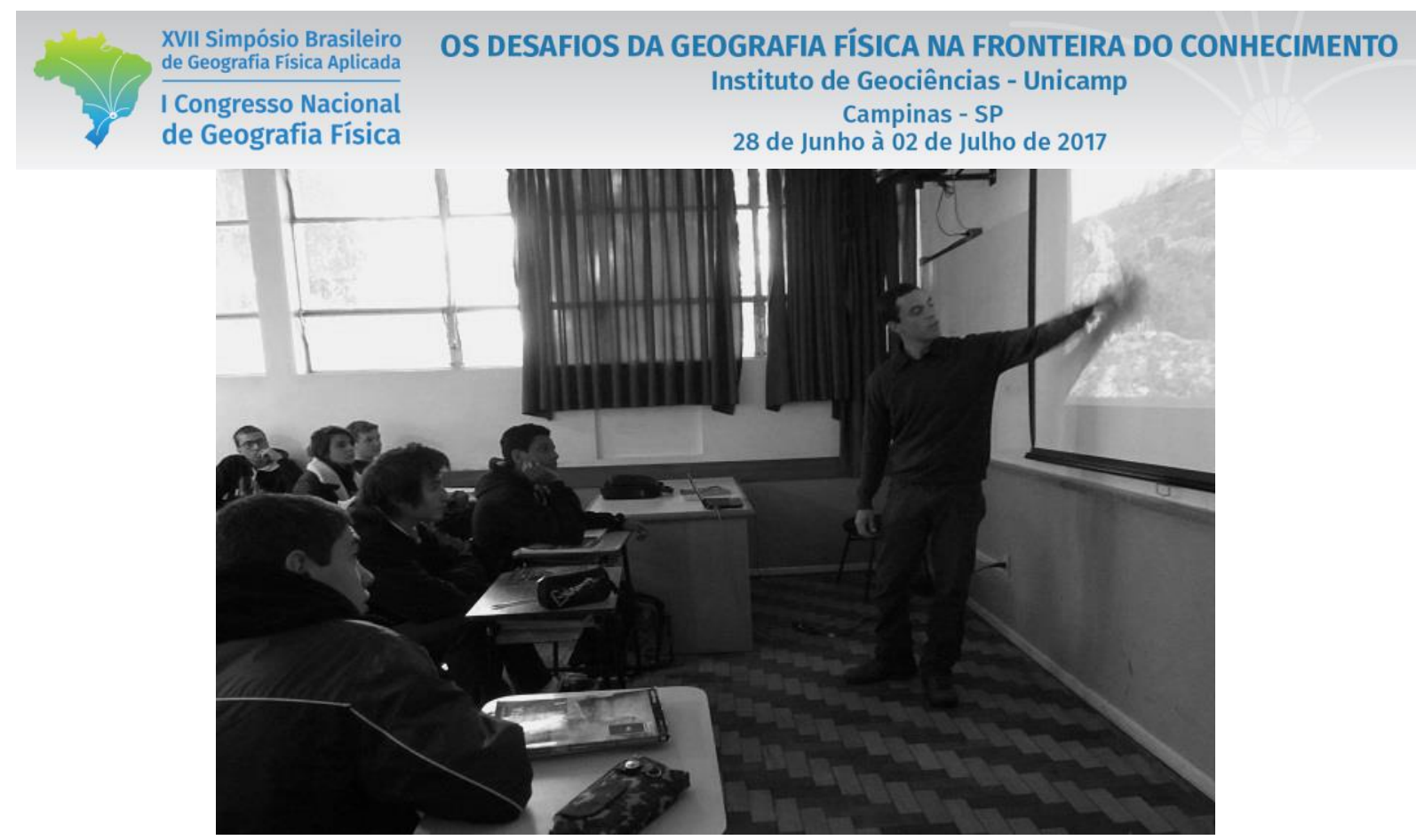

Figura 1- Desenvolvimento das aulas teóricas onde foram apresentados conceitos e imagens referentes à Biogeografia. Fonte: Autores.

Durante a trilha proposta (figura 2), os alunos se preocuparam em fotografar, questionar as características principais das plantas apresentadas. Muitos alunos se interessaram pelas as espécies abordadas, como formas, cores, hábitos assim como os diversos mecanismos que as plantas possuem para defesa, atração do polinizador e dispersão de sementes. No momento da revelação de todas essas curiosidades sem dúvida foi o ponto alto da atividade, pois prestavam a atenção a todos os detalhes.

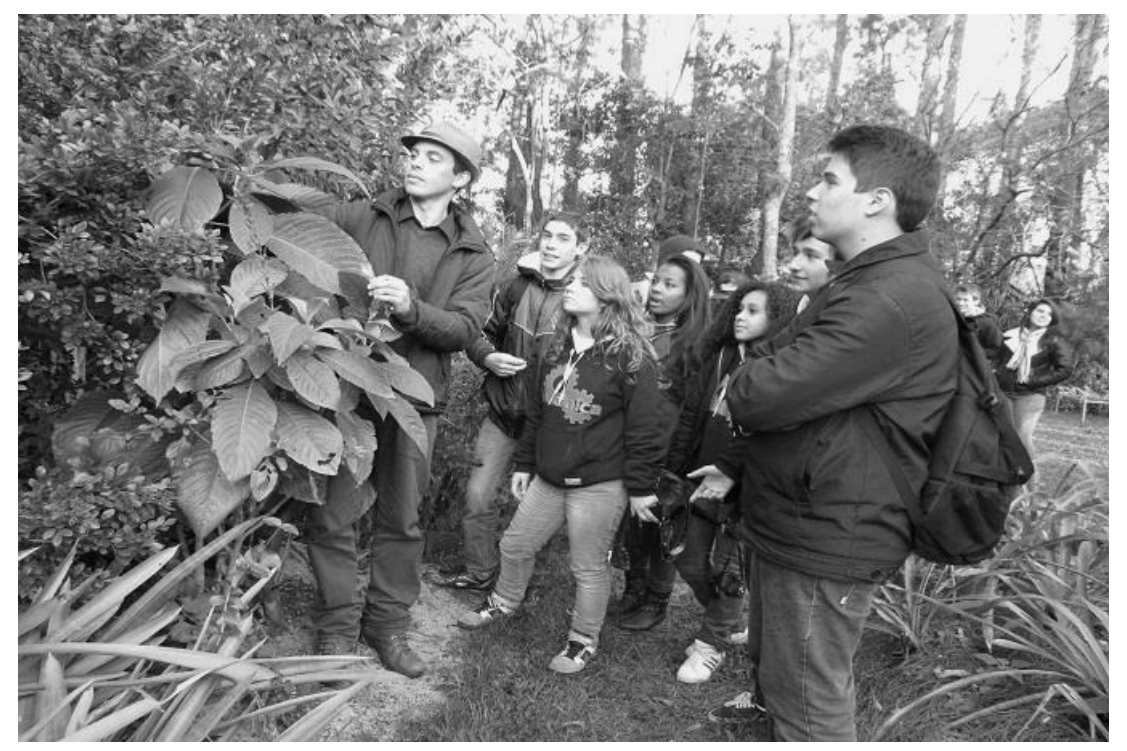

Figura 2 - Trilha na coleção do Colégio Politécnico da Universidade Federal de Santa Maria. Fonte: Autores. 


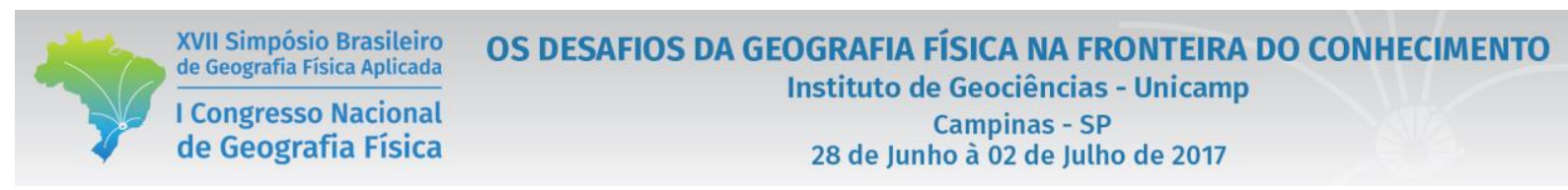

Durante a trilha (figura 3) foi esclarecido aos estudantes que mesmo as plantas não muito vistosas também possuem uma razão ecológica de existir e, que apesar de não possuírem belas flores grandes e coloridas, a planta exerce um papel fundamental no ecossistema. A metodologia empregada objetivou a integração sócio-ambiental, o conhecimento científico da natureza e a mudança de comportamento do homem em relação ao seu entorno.

Ao considerar um contexto atual, percebe-se a relevância da discussão sobre a Educação Ambiental na busca de solução de problemas sócio-ambientais. Como a ação proposta e desenvolvida corresponde a uma ferramenta ecológica ambiental, ela pode ser considerada uma possibilidade de expansão desta visão de Educação. Nela podem ser incluídas atividades dinâmicas e participativas onde os participantes recebam informações sobre: recursos naturais, uso racional e conservação dos mesmos, aspectos culturais, econômicos e históricos da região.

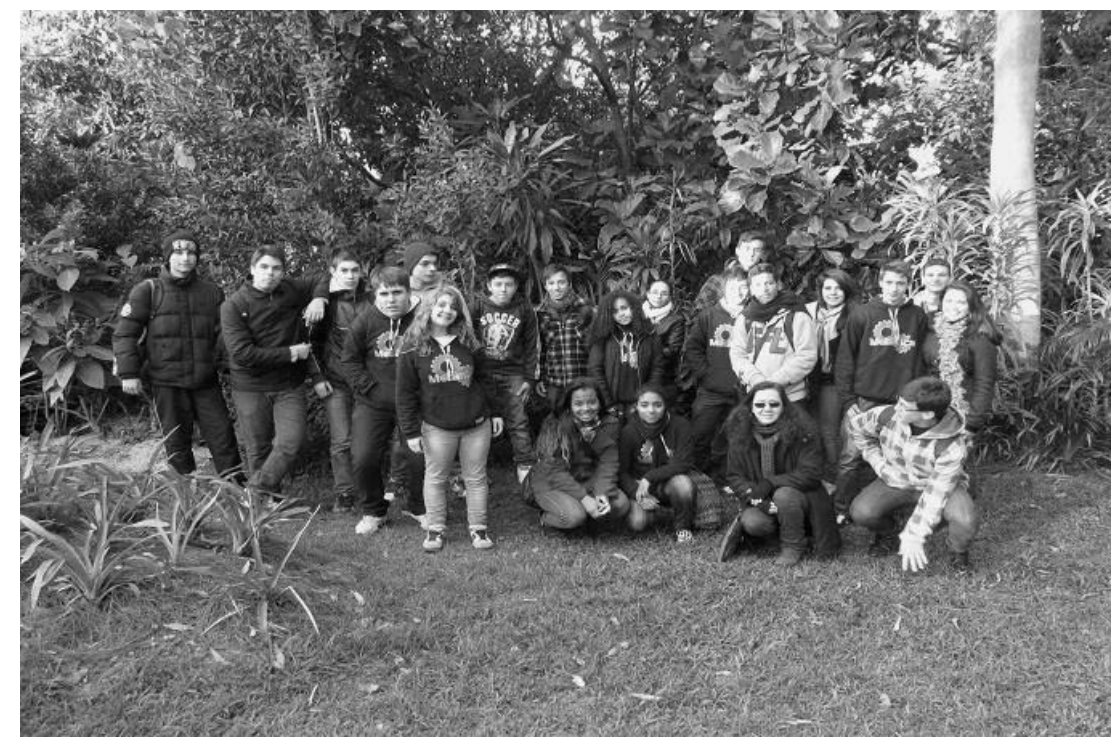

Figura 3 - Alunos do Colégio Técnico Industrial da Universidade Federal de Santa Maria, durante a trilha na Coleção Botânica do Colégio Politécnico da Universidade Federal de Santa Maria. Fonte: autores.

As atividades posteriores em sala de aula (figura 4) se desenvolveram muito bem, onde foram confeccionados cartogramas juntamente com fotografias de espécies registradas pelos próprios alunos, conforme a escolha dos mesmos. Durante o momento da elaboração diversos questionamentos foram levantados. Na Educação Ambiental formal ela permite a sensibilização e a fixação de conteúdos desenvolvidos em sala de aula. A ampliação da percepção ambiental é o principal objetivo ao se considerar as trilhas práticas ambientais. No processo de educação informal também ocorre uma atualização e melhora o conhecimento científico da natureza, ainda proporciona a ampliação da percepção 
ambiental dos participantes e proporciona o conhecimento da relação de causa e efeito da ação do homem na natureza. Permite, portanto, a construção de uma visão do ambiente natural como um processo histórico e cultural. Desta maneira, a educação é fundamental à formação do ser humano ao longo da vida, devemos, portanto, encará-la como uma construção permanente das pessoas, dos seus saberes, aptidões e da sua capacidade de enxergar e agir corretamente nas situações do cotidiano. Logo, a educação é uma ferramenta para a difusão de novas mentalidades, como a de preservar o meio ambiente, idéia bastante debatida na atualidade, tanto nas escolas quanto nos meios de comunicação, visto que os princípios ambientais têm sido inseridos cada vez mais cedo na vida escolar dos alunos, devido à grande relevância do assunto.

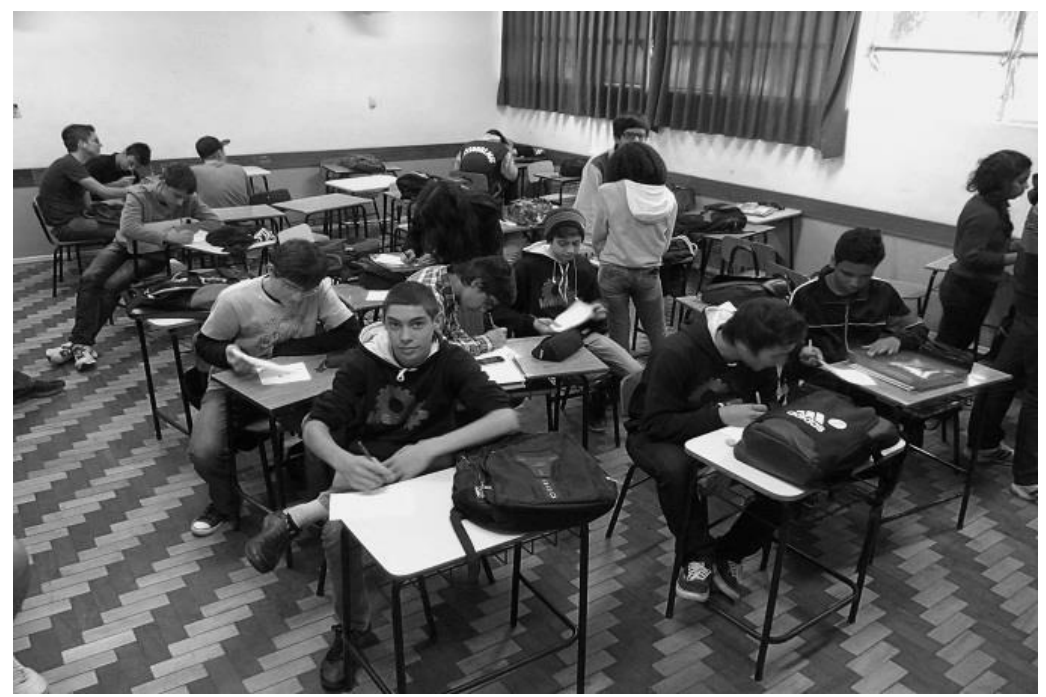

Figura 4 - Alunos durante as atividades de confecção dos cartogramas. Fonte: autores.

Por final, no encerramento da atividade, os trabalhos foram organizados em um painel (figura 5), sendo que o mesmo foi exposto próximo a sala de aula. Em uma avaliação o panorama da atividade, esta se tornou muito útil, pois pode trabalhar com elementos e conceitos da Geografia e da Biologia, mostrando que a interdisciplinaridade é algo a contribuir com o processo de aprendizado no aluno, trazendo os conceitos teóricos para a aplicação prática no cotidiano. 

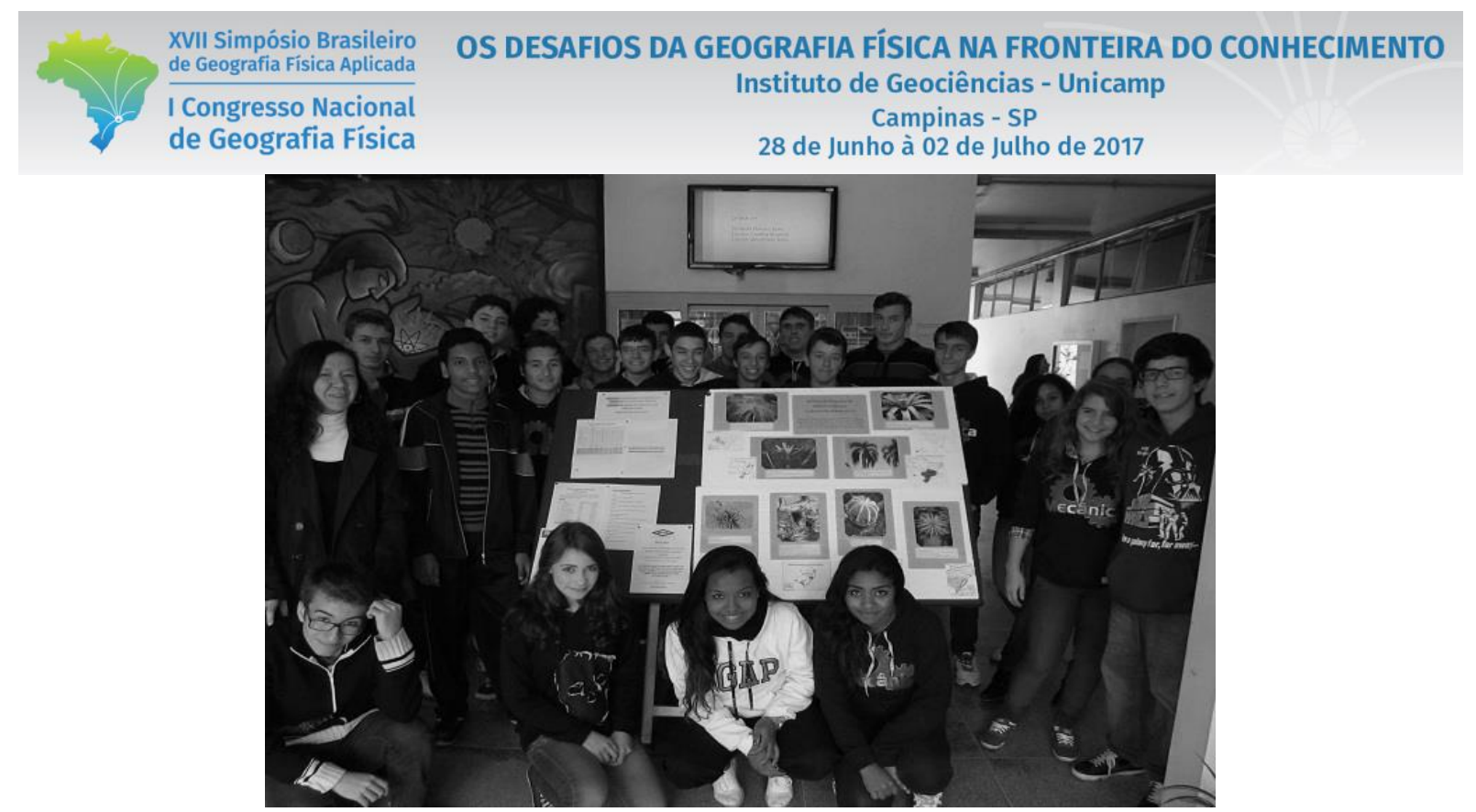

Figura 5 - Alunos e o painel confeccionado com os cartogramas. Fonte: autores.

Sendo assim, a presente ação buscou focar no objetivo de estimular a consciência ambiental, contribuindo com o meio ambiente e, consequentemente, melhorando as condições de vida dos cidadãos. Por se tratar de uma ação de extensão, ultrapassa os limites acadêmicos, possuindo uma face social, que se refere à outra proposta de educação ambiental.

\section{Considerações finais}

Após a finalização das ações propostas conclui-se que os objetivos foram positivamente alcançados, pois houve curiosidade e entendimento elementos naturais observados em cada um dos pontos selecionados no ambiente proposto. Deles foram estabelecidos pontos de observação e aproveitaram-se os elementos naturais vegetais que constam dentro da área percorrida.

Foram apresentadas características compatíveis com o conhecimento dos participantes, ou seja, espécies que os estudantes conheciam a partir de suas vivências e puderam reconhecer a função para a sociedade e/ou para a natureza. Também, durante a atividade, pode-se perceber que os estudantes valorizam a importância da temática abordada para sua evolução como aluno (para entendimento tanto da disciplina de Geografia e de Biologia, como a inter-relação entre essas áreas do conhecimento) e também para a sua formação acadêmica e como cidadão.

A atividade desenvolvida fora da sala de aula foi muito bem acolhida, e promoveu grande envolvimento entre os estudantes, o que permite concluir que trata-se de uma estratégia positiva, a partir da observação e descrição, para promover o aprendizado e a educação. Isso pôde ser percebido no reconhecimento de plantas presentes em nosso cotidiano durante a atividade o que agregou um novo conhecimento aos 
estudantes, estimulando-os a vivenciarem uma nova percepção perante o meio ambiente. Além disso, para os estudantes envolvidos nessa ação de extensão, foi esclarecedor conhecer as espécies ameaçadas de extinção no estado do Rio Grande do Sul.

\section{REFERÊNCIAS}

AB'SÁBER, A. N. Os domínios morfoclimáticos na América do Sul: primeira aproximação. Vegetalia: Escritos e Documentos. São José do Rio Preto:IBILCE-UNESP, n. 15 1977a. 17p.

AYOADE, J. Introdução a climatologia dos trópicos. São Paulo: Difel, 1986.

CHRISTOFOLETTI, A. Geomorfologia. São Paulo: Edgard Blücher, 1980.

GUERRA, A. Dicionário geológico-geomorfológico. 4. ed. Rio de Janeiro: IBGE, 1975.

HOLZ, M. Do mar ao deserto: A evolução do Rio Grande do Sul no tempo geológico. 2. ed. Porto Alegre: Ed. da UFRGS, 2003.

LINDMAN,C. A. M. A vegetação do Rio Grande do Sul (Brasil Austral). Porto Alegre: Livraria Universal de Echenique Irmãos \& Cia, 1906.

MARCATTO, C. Educação ambiental: conceitos e princípios. Belo Horizonte: FEAM, 2002.

MARCHIORI, J. N. C. Fitogeografia do Rio Grande do Sul. Campos Sulinos. Porto Alegre: EST, 2004.

MARCHIORI, J. N. C. Fitogeografia do Rio Grande do Sul. Campos Sulinos. Porto Alegre: EST, 2004.

MARTINS, M; SANO, P. Biodiversidade Tropical. São Paulo: Ed. da UNESP, 2009, 128 p.

RAMBO, B. A fisionomia do Rio Grande do Sul. Ensaio de monografia natural. São Leopoldo: 3. ed, Ed. da UNISINOS, 1956. $456 \mathrm{p}$.

RAMBO, B. Viagem ao Sudoeste do Rio Grande do Sul. Santa Maria: Ed. da UFSM, 2014. 200 p.

ROMARIZ, D. A. Biogeografia: temas e conceitos. São Paulo: Scortecci, 2012.

ROOS, J. L. S. Geografia do Brasil. 6. ed. São Paulo: Edusp, v. 1, 1996.

SEARA FILHO, G. Apontamentos de introdução à educação ambiental. Revista Ambiental, ano 1, v. 1, 1987, p. 4044

TROPPMAIR, H. Biogeografia e o Meio Ambiente. 9. ed. Rio de Janeiro: Technical Books, 2012.

VIEIRA, E. F. Rio Grande do Sul. Geografia física e vegetação. Porto Alegre: Sagra, 1984. 